\title{
TITLE: FREE-ELECTRON LASER SOURCES OF EXTREME-ULTRAVIOLET RADIATION AND THEIR VACUUM REQUIREMENTS
}

AUTHOR(S): BRIAN E. NEWNAM, CLS-6

\author{
SUBMITTED TO: Being published in AIP Conference Proceedings of Topical Conference \\ on Vacuum Design of Synchrotron Light Sources at Argonne National \\ Laboratory, November 13-15, 1990
}

By acceptance of this anticle the publisher recognzes that the U.S. Governement retains a nonexclusive, royalty-free license to publish or reproduce the published form of this contribution or to allow others 10 do so, for U.S. Government purposes.

The Los Alamos National Laboratory requests that the publisher identify this article as work performed under the auspices of the U.S. Department of Energy

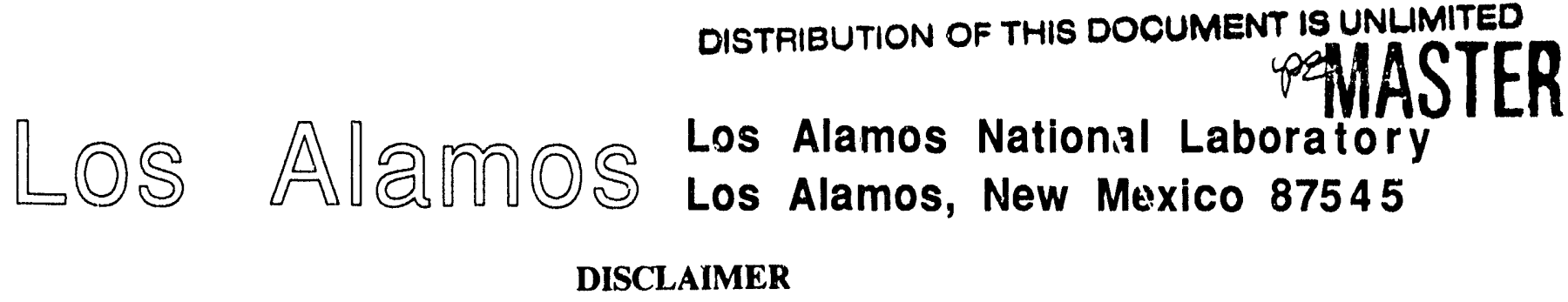

This report was prepared as an account of work sponsored by an agency of the United States Government. Neither the United States Government nor any agency thureof, nor any of their employees, makes any warranty, express or implied, or assumes any legal liability or responsibility for the accuracy, completeness, or usefulness of any information, apparatus, product, or process disclosed, or represents that its use would not infringe privately owned rights. Reference herein to any specific commercial product, process, or service by trade name, trademark, manufacturer, or otherwise does not necessarily constitute or imply its endorsement, recommendation, or favoring by the United States Government or any agency thereof. The views and opinions of authors expressed herein do not necessarily state or reflect those of the United States Government or any agency thereof. 


\title{
EREE-ELECTRON LASER SOURCES OF EXTREME-ULTRAVIOLET RADIATION
} AND THEIR VACUUM REQUIREMENTS *

\author{
Brian E. Newnam \\ Chemical and Laser Sciences Division \\ Los Alamos National Laboratory \\ Los Alamos, New Mexico 87545
}

\begin{abstract}
Recent development of free-electron laser (EEL) component technologies should enable these devices to operate in the extremeultraviolet, well below $100 \mathrm{~mm}$. When fully developed, EEIs represent the next generation of coherent-radiation sources with peak- and average-power outputs surpassing those of any existing, continuously tunable photon source by many orders of magnitude. An rf-linacbased, multiple-FEL facility, spanning the spectral range from $1 \mathrm{~nm}$ to $100 \mu \mathrm{m}$, is proposed. To enable such a facility to operate without significant degradation over long periods, contamination of certain of the FEL components must be prevented. Requirements for ultra-high vacuum and restricted contamination from outgassing from chamber walls are discussed.
\end{abstract}

\section{INTRODUCTION}

Eree-electron lasers appear to be the natural finale in the progression of light sources based on radiation from relativistic electrons passing through magnetic undulators. Since 1977, more than one-dozen FEL Oscillators and amplifiers have produced coherent radiation over a broad spectral range extending from $240 \mathrm{~nm}$ in the ultraviolet 1,2 to millimeter wavelengths as shown in Fig. 1 . Even shorter wavelengths (down to $106 \mathrm{~nm}$ ) have been produced by coherent spontaneous emission from EEL amplifiers, albeit at very low power.3,4 These successes have encouraged FEL researchers to examine the parameters required for FEL operation in the extreme ultraviolet (XUV) below $100 \mathrm{~nm}$ where no powerful, tunable, coherent-radiation source presently exists.

Extending FELs to ever shorter wavelengths, however, is inherently difficult since the gain decreases monotonically with the square-root of the wavelength, 5,6 and below $100 \mathrm{~nm}$ the available mirrors for resonators have comparatively low reflectance, generally $<50$. With such mirrors, the small-signal power gain for a single pass through the magnetic undulator must exceed 4008 to reach the threshold for oscillation. Such high gain can be attained with large peak electron-pulse current $(>100 \mathrm{~A})$ and long undulators comprising several hundred periods. Howevex, long undulators have small homogeneous gain bandwidth proportional to $1 / N$, where $\mathrm{N}$ is the number of periods. Since the gain is limited by both the transverse electron beam emittance and longitudinal energy spread, it is essential that the accelerators deliver very bright (ratio of peak current and norm-

*Work supported by Los Alamos National Laboratory Program Development Funds and performed under the auspices of the U. S. Dept. of Energy. 
alized emittance-squared) electron beams.

Storage rings and ef linear accelerators (rf linacs) with highbrightness injectors are presently the only sources of electron beams with sufficiently high peak current and low emittance to drive XUV EELs. Storage rings (SR) with long straight sections for XIV EEI oscillators are being constructed by Madey's7-11 group at Duke University and designed by the DELTA12,13 group at the University of Dortmund. These systems should provide good spectral stability for spectroscopic measurements and have variable pulsewidth capability. System design and component development for rf-linac-based XUV EELs have been pursued by Newnam14-25 and co-workers at Los Alamos National Laboratory since 1984. More recently, Ben-zvi et al.26 at Brookhaven National Laboratory have proposed a VUV-EEI amplifier $(100-200 \mathrm{~nm})$ to be driven by a superconducting rf linac. Rf-linac FELs should generate high average power $\left(\sim 10^{2}\right.$ W) in the XUV depending on the duty factor ( 100 times more power than SR FELs), and a series of EELs can be driven simultaneously by one linac.

The essential elements of an rf-linac-EEL oscillator, as illustrated in Eig. 2, are the electron beam produced by an accelerator, a magnetic undulator in which the electrons oscillate transversely and emit (or absorb) light, and the resonator mirrors. By varying either the electron energy, the magnet separation, or the magnetic field on axis, the wavelength can be tuned continuously over a broad range. The laser radiation is coherent, polarized, and nearly diffraction

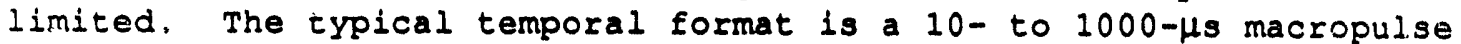
train of 1- to 10-ps micropulses with r1- to 100-ns separation and with an arbitrary macropulse repetition rate. By slight detuning of the resonator length, the spectral bandwidth of radiation from EEL oscillators can be varied from the narrow Fourier-transform limit of the ps pulses to several per cent with sidebands.

Los Alamos National Laboratory,27-30 Stanford University, 31,32 and Boeing Aerospace Company33,34 have operated rf-linac-driven FEL oscillators in the visible and near infrared for a cumulative total of several thousand hours. Experience with these systems has provided invaluable insight and data with which to design rf-linacdriven EEI oscillators (and possibly high-gain, single-pass amplifiers) 35,36 for operation in the xUV spectral range. An important distinction of the Los Alamos IR FEL is its very high 500-A peak current capability and correspondingly large single-pass optical gain from a short, $1-\mathrm{m}$ undulator (2508 small-signal gain/pass at $10 \mu \mathrm{m}$ with 300- to 400-A peak current).28,29 such are the magnitudes of the parameters that will be required for operation of FEL oscillators in the XUV. With recent significant improvements to the primary components, it only remains to construct a high-brightness linac with energy $2200 \mathrm{MeV}$ to verify the feasibility of operating below $100 \mathrm{~nm}$.

The accelerator and optical components and numerical simulation codes that will be needed to design and construct the nextgeneration XUV-FEL light sources have been under active development at Los Alamos for the last five years. These components include the laser photoinjector, multifacet XUV resonator mirrors, and highprecision undulators. For each of these technologies, operation in high vacuum is imperative. Photoemissive surfaces with high quantum efficiency ( $\$ 10 \%$ ) and reflector films susceptible to oxidation and/or 


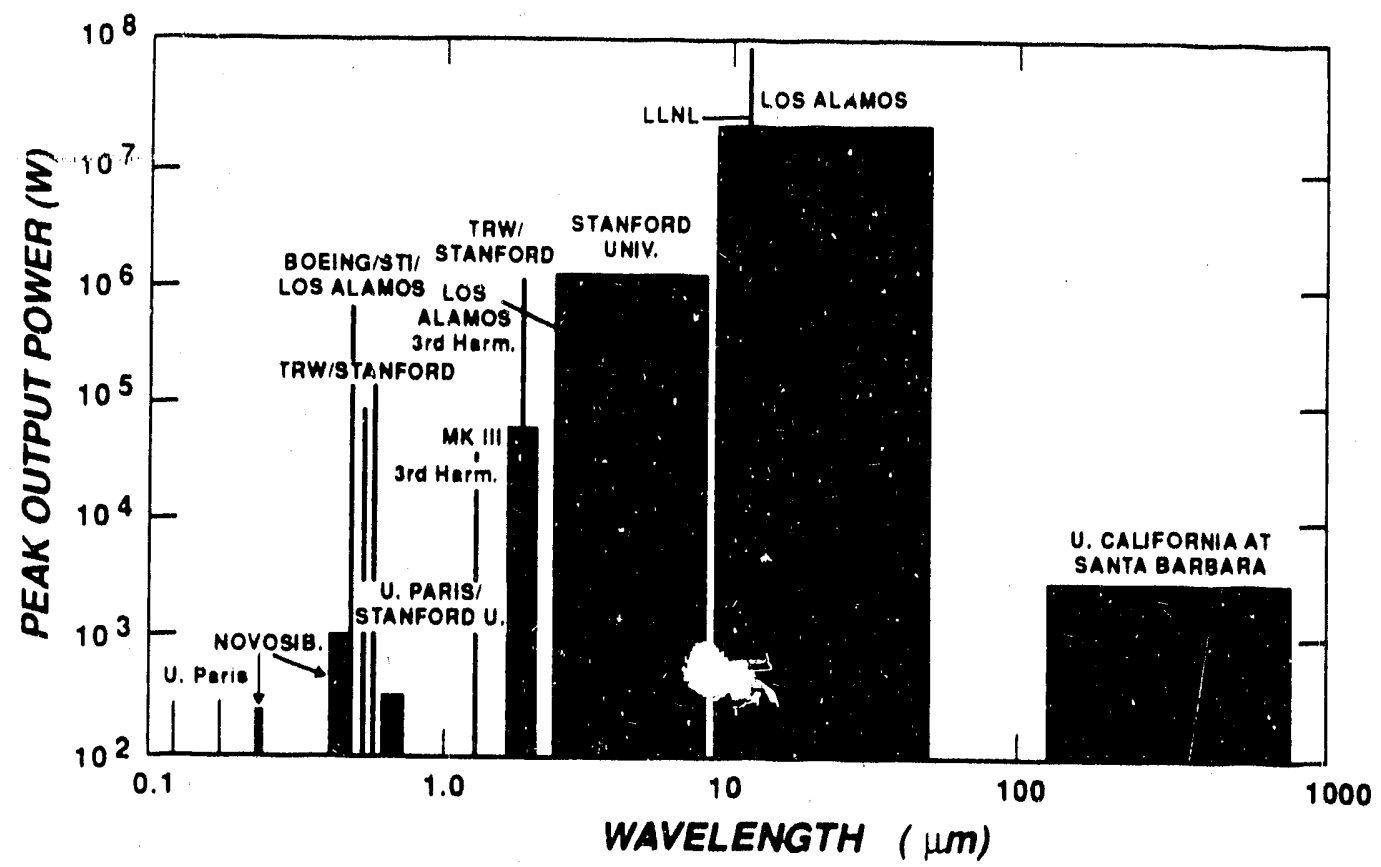

Fig.1. Succesful free-electron laser operation in the nearultraviolet to the far-infrared provides the experience base for extension below $0.1 \mu \mathrm{m}$. (The weak output at the two vov wavelengths was coherent spontaneous emission from electrons bunched within an undulator by an external 532-nm laser. 3 )

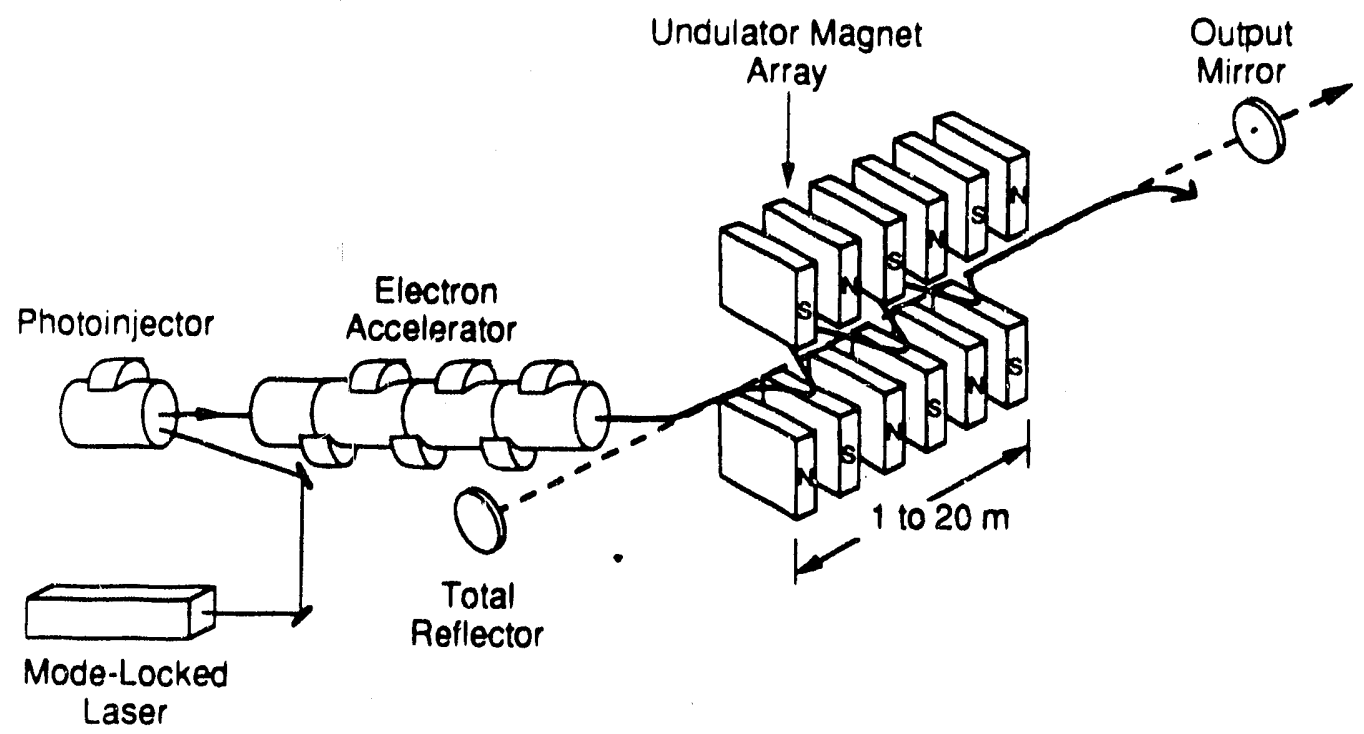

Fig. 2. Basic schematic of an rf-linac-driven free-electron laser oscillator showing the laser photoinjector, if linac, magnetic undulator, and optical resonator. 
carbon film buildup, e.g., Al, Si, Rh, and Ag, will require ultrahigh vacuums to maintain satisfactory performance over a conveniently long period. Less stringent vacuum levels wili suffice if photocathodes with moderate quantum efficiencies, e.g. 10-3, can be used. For the reflectors, carbon contamination will have to be controlled locally with ion pumps, and coatings may have to be cleaned and refreshed periodically. Finally, an adequate vacuum must exist in the small-diameter beam tubes within the magnetic undulatoj:s to prevent electron-beam emittance growth as a result of ion trapping. For single-pass machines, moderate vacuum levels should be adequate, but the usual 10-9 to 10-10 Torr UHV level will be necessary in storage-ring FEIs to maintain long beam lifetime.

In the following two sections, we will describe the design and operating characteristics of an XUV-FEL user facility as proposed by Los Alamos National Laboratory, and then discuss the vacuum environments necessary for the three FEL components introduced above.

\section{PROROSED XUV-IR FEL USER FACILIYYY}

EEI configuration: Based on considerable technical progress to date (primarily supported by the U.S. Strategic Defense Initiative GroundBased Laser Program plus Department of Energy investments in future XUV-FEL extensions), LOs Alamos National Laboratory has designed a series of FELs with output ranging into the soft $x$-ray spectral region for integration into a proposed XUV-IR FEI national user facility for scientific experimentation and industrial applications. This design uses one high-energy rf linac ( $51 \mathrm{GeV}$ ) to drive a series of seven FEI oscillators that will produce trains of coherent, picosecond pulses spanning the spectral range from 1 to $500 \mathrm{~nm}$. A second series of three EEL oscillators, driven by a separate $60-\mathrm{MeV}$ rf linac synchronized with the first, will produce wavelengths from the visible to the far infrared from $0.5 \mu \mathrm{m}$ to $100 \mu \mathrm{m}$. Over the range of high single-pass FEL gain, the predicted peak- and averageoutput powers, especially below $300 \mathrm{~nm}$, should surpass the capabilities of any existing, continuously tunable photon source by four to seven orders of magnitude. In addition, the spectral bandwidth may be sufficiently narrow, e.g. $\leq 10.4$ at $100 \mathrm{ev}$, that use of a monochromator may be optional for many applications.

The conceptual design of the proposed Los Alamos XUV EEL facility is shown in Fig. 3 , and design specifics are given in Table I. The shortest-wavelength oscillators are ordered first in the sequence since they require the highest-quality electron beam; the gain at longer wavelengths is less affected by beam degradation. Even so, all of the oscillators are designed to perturb the electron beam energy only very slightly, with the energy-extraction efficiency being $0.1 \%$ or less. Further beam degradation by wakefield effects in the beamline and magnetic undulator will be avoided by minimizing discontinuities. The number of oscillators may be increased arbitrarily, consistent with the amount of accumulated energy spread and/or emittance degradation in the electron beam that can be tolerated. The operating wavelengths of each of the FELs will either be tuned as a group by varying the electron energy or tuned independently over a smaller range by adjusting the undulator gaps. 


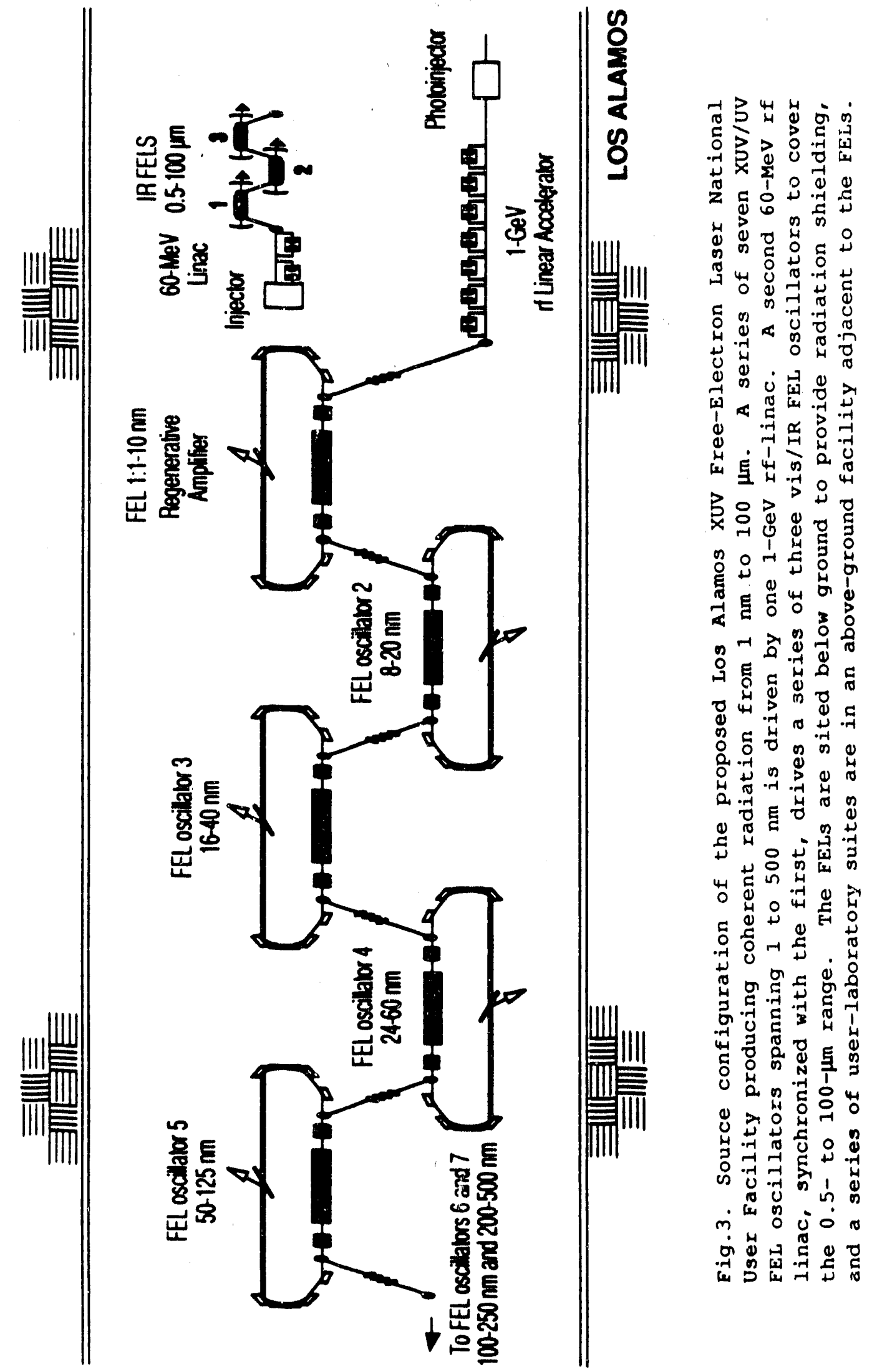


Table I. Parameters for the proposed Los Alamos rf-linac-driven xuv-ir EeL user facility

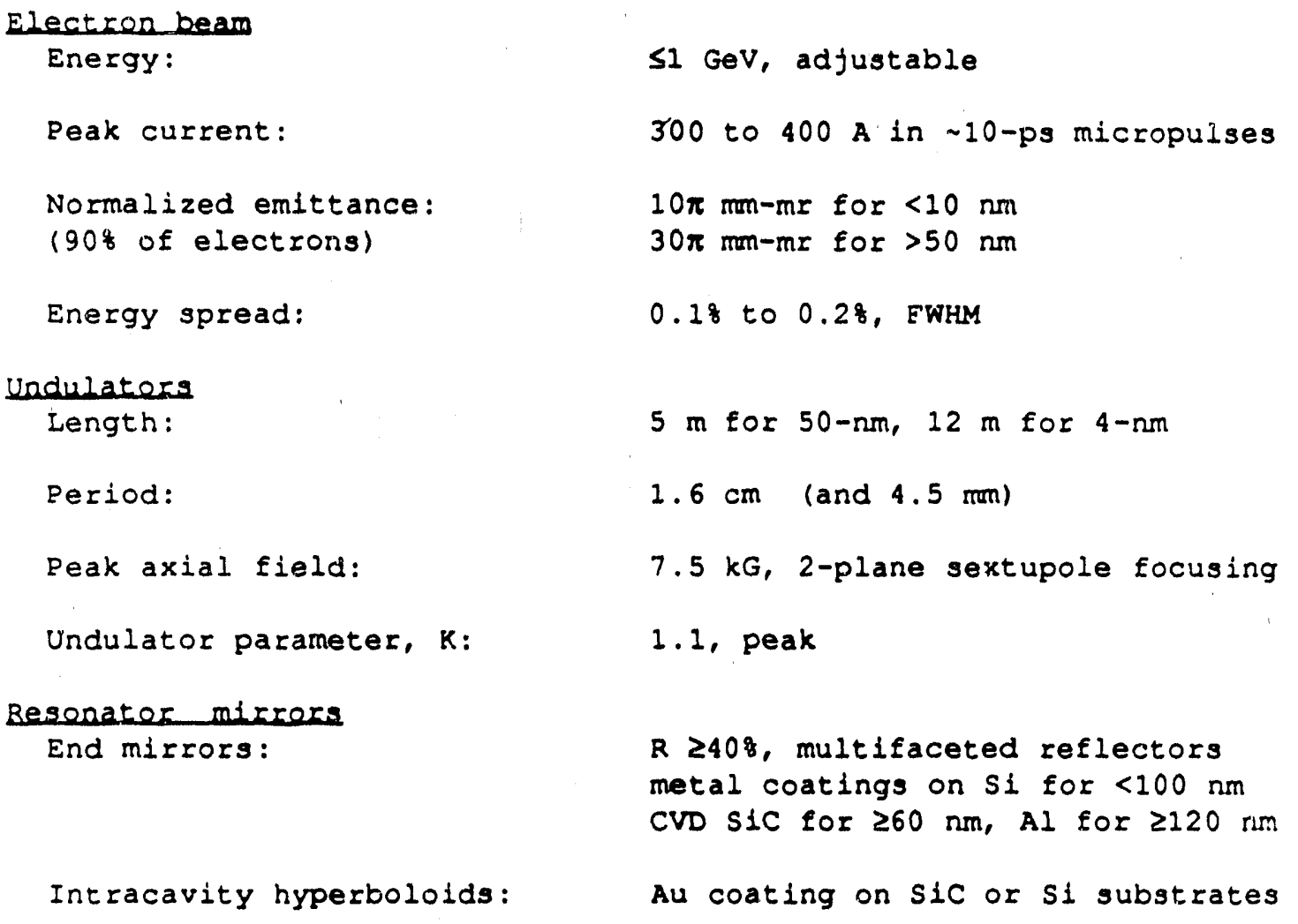

A mirror gallery has been devised to deliver radiation from any of the ten EELs to each of six experimental rooms devoted to physical-, chemical-, materials-, blological-, and medical sciences as well as industrial applications. 37 According to the participants at the 1988 OSA Topical Meeting on FEL Applications in the Ultraviolet, 38 the unique capabilities of such a facility will open numerous, new research opportunities in these disciplines.

At this time, the of linac is designed for room-temperature operation. All of the past Los Alamos infrared FEL experiments have used an L-band (1.3 GHz), side-coupled, standing-wave if linac operated at slightly above ambient temperature. Design calculations for advanced, standing-wave linac structures have been performed from $100 \mathrm{MeV}$ to $1 \mathrm{GeV}$ for an XUV FEL. Cryogenic and superconducting (at $4 \mathrm{~K})$ zavity options also are being examined, because they offer potential advantages of $\mathrm{cw}$ macropilse operation, improved pulse-topulse stability, and reduced electrical cost due to lower power dissipation in the linac structure. However, the capability of either of these altern-te conflgurations to generate several-hundred amperes of peak current has not yet been demonstrated.

Rredicted XUY-IB Fri, Output: We have performed 3-D numerical simulations using the EEL code FELEX 39 and its derivatives to predict 
the single-pass and multiple-pass gain in XUV-FEL resonators, and the spectral bandwidth, output power, and spectral brightness versus wavelength. Tables II-IV provide an abbreviated sumary. Electrical power cost considerations will limit the year-long average duty factor to 1 f for ambient-temperature linac structures, but occasional operation at $210 \%$ duty $1 \mathrm{~s}$ feastble with proper cooling of the accelerator cavities, and 1008 duty may be possible if either a cryogenic or a superconducting linac design is adopted. Practically, the duty factor will be limited by laser-induced thermal distortion of the FEL resonator mirrors.40 The latter limitation can be avoided if enough ( 104) single-pass gain can be realized in FEL amplifiers based on self-amplification of spontaneous emission (SASE).

Table II. Radiation properties of the proposed Los Alamos rf-linac-driven xuv-ir EEL user facility

\begin{tabular}{|c|c|}
\hline Micropulse duratiot: & 10-20 ps (EWHM) compressible to <2 ps \\
\hline Micropulse repetition rate: & $3 \times 107 \mathrm{~Hz}$ \\
\hline Macropulse duration: & 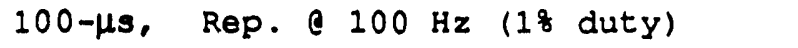 \\
\hline Eacility wavelength span: & $\begin{array}{l}1 \mathrm{~nm} \text { to } 500 \mathrm{~nm}, 7 \text { EEL oscillators } \\
(0.5-100 \mu \mathrm{m}, 3 \mathrm{IR} \text { EELs } \mathrm{w} / 2 \mathrm{nd} 60-\mathrm{MeV} \\
\text { linac) }\end{array}$ \\
\hline Spectral bandwidth: & $\begin{array}{l}1 \mathrm{~cm}^{-1} \text { Fourier-transform limit } \\
\text { for single, 10-ps pulses } \\
10^{-4} \mathrm{w} / 25 \mathrm{klystrons,} \mathrm{possibly} \mathrm{10-5} \\
\text { up to }-18 \text { if sidebands are allowed }\end{array}$ \\
\hline Polarization: & Linear, w/circular/elliptical options \\
\hline Temporal coherence: & Limited by micropulse Fourier trans. \\
\hline
\end{tabular}

cemparison with sunchrotron Ifoht sources: It is of interest to compare the predicted stimulated-emission output from FELs with the spontaneous-emission output generated from existing and planned synchrotron light sources that have magnetic insertion devices (wigglers and undulators). Figure 4 presents a comparison of timeaveraged spectral brightness (photons/s/(mm-mr)2/0.1\% bandwidth) delivered on target as a function of wavelength, and Table IV lists the flux and power output at $100 \mathrm{~nm}$ predicted for an rf-linac-EEL along with that of two storage-ring devices. At 10 ev $(124 \mathrm{~nm})$ the EELs will produce 104 to 106 higher average spectral filux on target; at $100 \mathrm{eV}(12 \mathrm{~nm})$, the EEL advantage will diecrease to a factor of $10^{2}$ to 104, depending on the FEL duty factor. Moreover, the corresponding peak flux output of the rf-linac FEL ( 1 is duty) will exceed that of synchrotron undulators by an additional factor of $10^{3}$. 
Table III. Photon power and brightness predictions for the proposed Los Alamos rf-linac-driven xuv-is FEL user facility

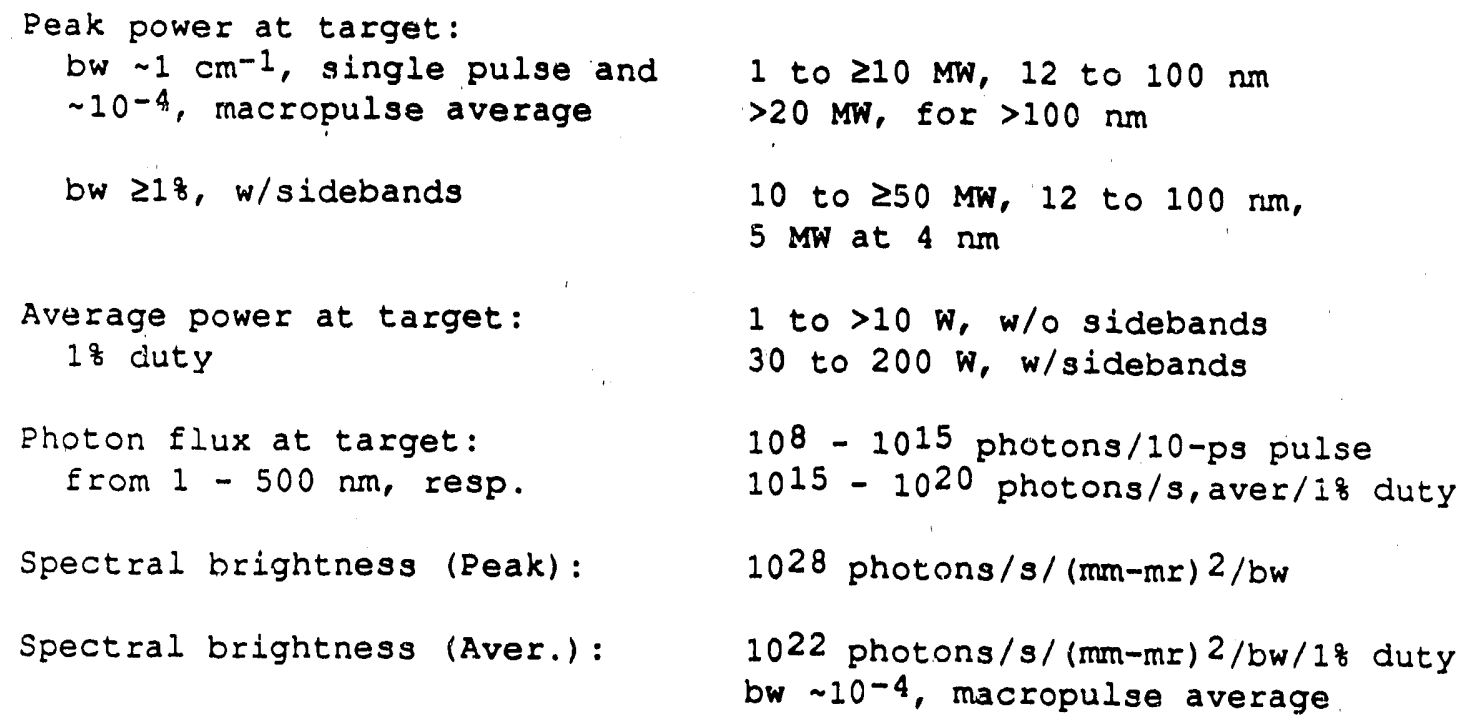

Table IV. Output comparison of rf-linac-driven EEL and synchrotron radiation sources at $100 \mathrm{~nm}$

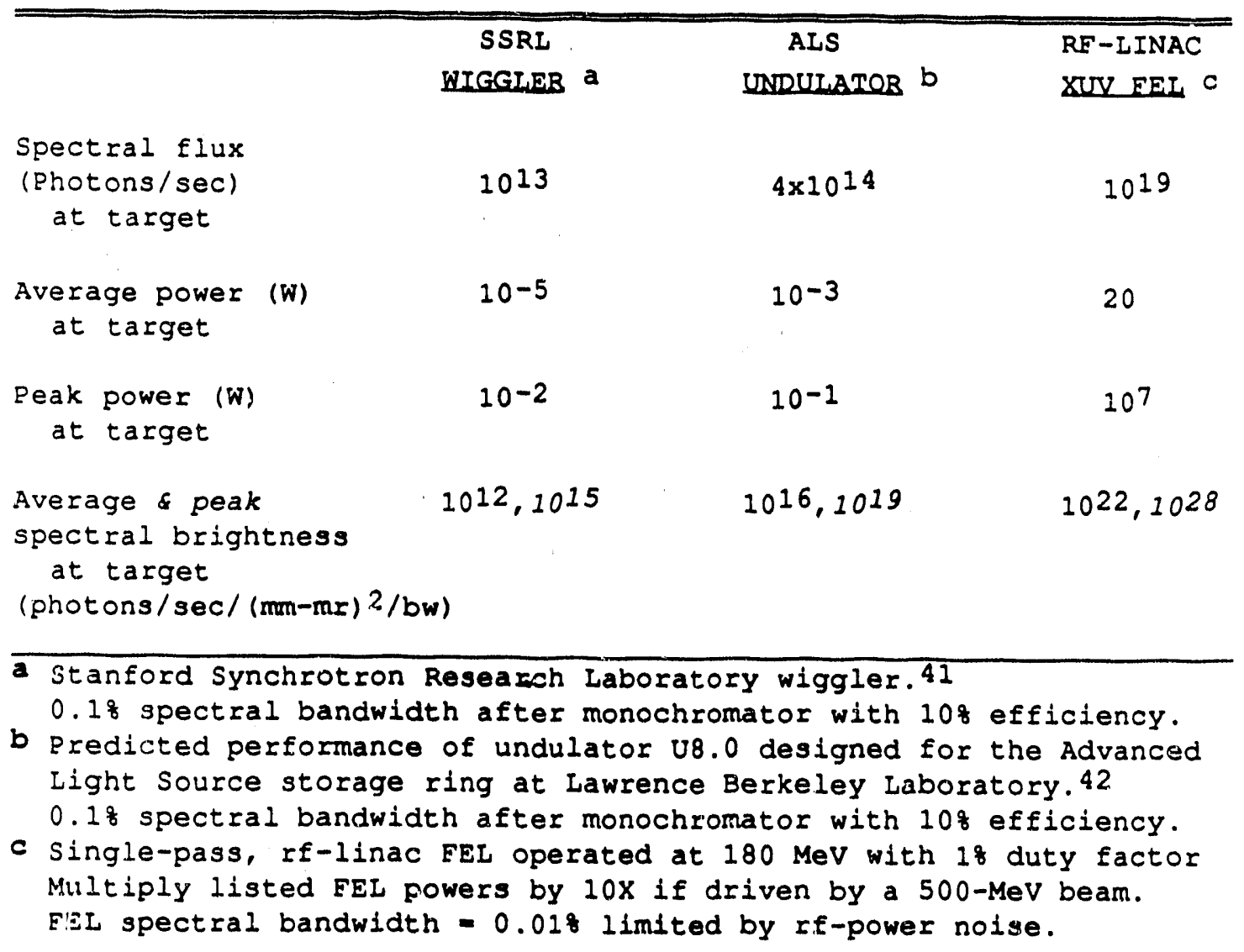




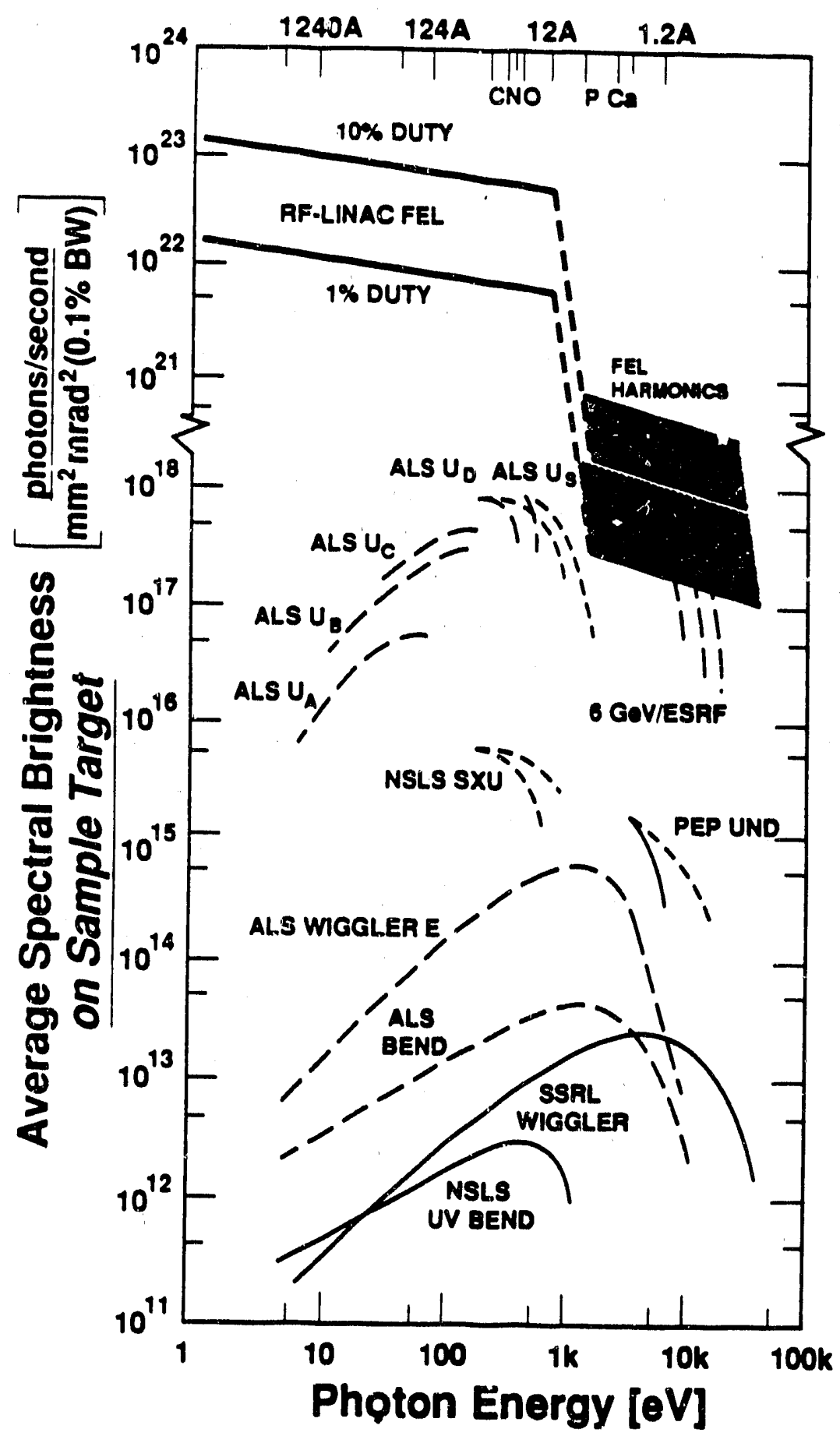

Fig.4. Time-average spectral brightness (delivered on target) of FELs will far exceed that of the most powerful storage rings designed with insertion devices (undulators and wigglers). The EEL curves were calculated for the Los Alamos rf-linac FEL design, and a monochromator efficiency of $10 \%$ was applied to the published undulator output curves. To convert the time-average curves to peak values, the appropriate conversion factors are 3 x 105 for the FFL output e if duty and $\sim 3 \times 10^{2}$ for the storage-ring insertion devices. 
Qverview: For future FELs built to operate in the XUV, the vacuum environment will have a major impact on three primary components. These are the electron injector, resonator mirrors, and the undulator beam tube; their respective vacuum requirements are summarized in Table $V$. Furthermore, the vacuum requirements will depend to a large extent on what type of electron source is used. Storage rings are inherently not concerned with photoinjectors, but instead they must have high enough vacuum to assure a sufficiently long lifetime for the recirculating electron (or positron) beam. On the other hand, if linacs, as single-pass systems (or at most several-passes in a recyclotron mode), do not pose electron-beam lifetime concerns, but a contaminated photoinjector cathode will reduce the available beam current and lower the EEL gain.

Table $V$. Vacuum requirements for XUV-EEL oscillators for two bright electron sources

\begin{tabular}{lcc}
\hline EEI compenent & BF-Inoc & Sterage Ring \\
Photo-Injector & $10-10 \mathrm{~T}$ & $\mathrm{~N} . \mathrm{A}$. \\
Resonator Mirrors & $\sim 10-10 \mathrm{~T}$ & $-10-10 \mathrm{~T}$ \\
Undulator Tube & $<10-3 \mathrm{~T}$ & $\leq 10-9 \mathrm{~T}$ \\
\hline
\end{tabular}

Contamination of the resonator mirrors must be prevented and/or controlled in FEL oscillators driven by both SR and rf-linac electron sources. Mirror contamination will reduce the reflectance, raise the gain threshold for lasing, and decrease the steady-state output power. With sufficient single-pass gain (>104) to obtain exponential rise of the laser power through a long amplifier undulator, mirror problems would not exist. However, such high gain will very difficult to attain. Although a resonacor is more complex than a simple amplifier, it allows for reduced requirements on the electron beam and undulator. The single-pass gain (<103) required for XUV-EEL oscillators can be achieved with 10-100x lower electron beam brightness and undulators with half as nany periods as needed for an amplifier starting from noise. Additionally, contaminated external beam-steering mirrors will reduce the usful power on target for either oscillator or amplifiex configuration, and excess absorption of the incident energy will distort the mirror surface figure, thereby degrading the beam brightness.

In a storage ring, the vacuum quality within the narrow undulator beam tube must again be good enough to prevent significant degradation of the beam lifetime via scatter losses. In an rf-linac FEL, it must be only good enough to preclude plasma effects that could increase the emittance. The following paragraphs provide additional details on the vacuum requirements for each of these three element.s. 
Rhotoiniector cathede: The paramount importance of a high-brightness electron beam (defined as $2 \times$ ratio of peak current and normalized emittance-squared) for short-wavelength EELs has been emphasized in the Introduction. As an example, Goldstein et al.24 determined from 3-D numerical simulations that a 12-nm FEL oscillator will require a beam brightness of $1.2 \times 1011 \mathrm{~A} /(\mathrm{m}-\mathrm{z})^{2}$, corresponding to a peak current of 300 A and normalized transverse emittance of $23 \pi \mathrm{mm}-\mathrm{mr}$ ( 908 of particles), with energy spread of 0.18 (FWHM) at $535 \mathrm{MeV}$. Until the development and experimental demonstration of the laser photoinjector by Fraser and Sheffield, 43-45 electron beams with such high brightness had not been generated in an if linac. (The beam brightness capabilities of thermionic, dispenser, and semiconductor photocathode injectors are $0.08,2$, and $30 \times 1011 \mathrm{~A} /(\mathrm{m}-\mathrm{rad}) 2$, respectively. 45 ]

As shown in Fig. 5, a photocathode positioned on the end wall of the first accelerating cavity is irradiated by a train of ps-duration, visible to ultraviolet laser pulses. By applying a very high accelerating gradient, e.g., $30 \mathrm{MeV} / \mathrm{m}$, the photoelectrons attain a relativistic energy of 1 to $>3 \mathrm{MeV}$ in the first cavity, thereby minimizing their susceptibility to perturbations that cause emittance growth. The following photocathodes with varying levels of quantum efficiencies (QE) are being used in FEL injectors: CsK $2 \mathrm{Sb}$ ( $S 108$ QE)

at Los Alamos National Laboratory, 45,46 yttrium (0.18 QE) at Brookhaven National Laboratory, 47 and LaB6 $(0.01 \%$ QE) at Stanford University. 48

The Csk2Sb cathode is most susceptible to poisoning by contamination and must be operated in high vacuum of $10^{-10}$ Torr in order to have a practical lifetime with $Q E>1 \%$. Recent lifetime measurements of this cathode (see Fig. 6), while mounted within the photoinjector cavity at $2 \times 10^{-10}$ Tors and without laser irradiation, indicated that the $Q E$ declined only from 108 to 8 if in a 36-hour period followed by no change until the test ended at 68 hours. 49 However, in the presence of full rf-drive power, Los Alamos experimenters found that $\mathrm{CsK}_{2} \mathrm{Sb}$ photocathodes have lifetimes Iimited to one to two days. The degradation occurs only when the accelerating $r f$ power is applied. It is suspected that water vapor and carbonaceous gas compounds, desorbed from the cavity walls of the photoinjector, poison the cathode. Evidence of substantial outgassing, with both rf power applied and drive-laser illumination of the cathode, was the large pressure rise measured in the photoinjector cavity.49 Also, addition of $\mathrm{H}_{2}$ and $\mathrm{N}_{2}$ gases at pressures >10-8 Torr had no deleterious effect. These observations are in accord with the experfence at NSIS50 and CERN51 where the synchrotron radiation striking the metal chamber walls causes photostimulated desorption of $\mathrm{H}_{2} \mathrm{O}, \mathrm{CO}, \mathrm{CO}_{2}$, and $\mathrm{CH}_{4}$. As the photodesorption yield of these gases declines with accumulated radiation dose, the beam lifetime is observed to increase.

With the objective of producing 5-10 nc of charge per each 10-ps micropulse, Los Alamos scientises have determined that the lifetime of semiconductor photocathodes can be increased by use of more stable cathodes and by exposing the photoinjector accelerating cavities to high if fields for long periods. Their first cs3Sb photo- 


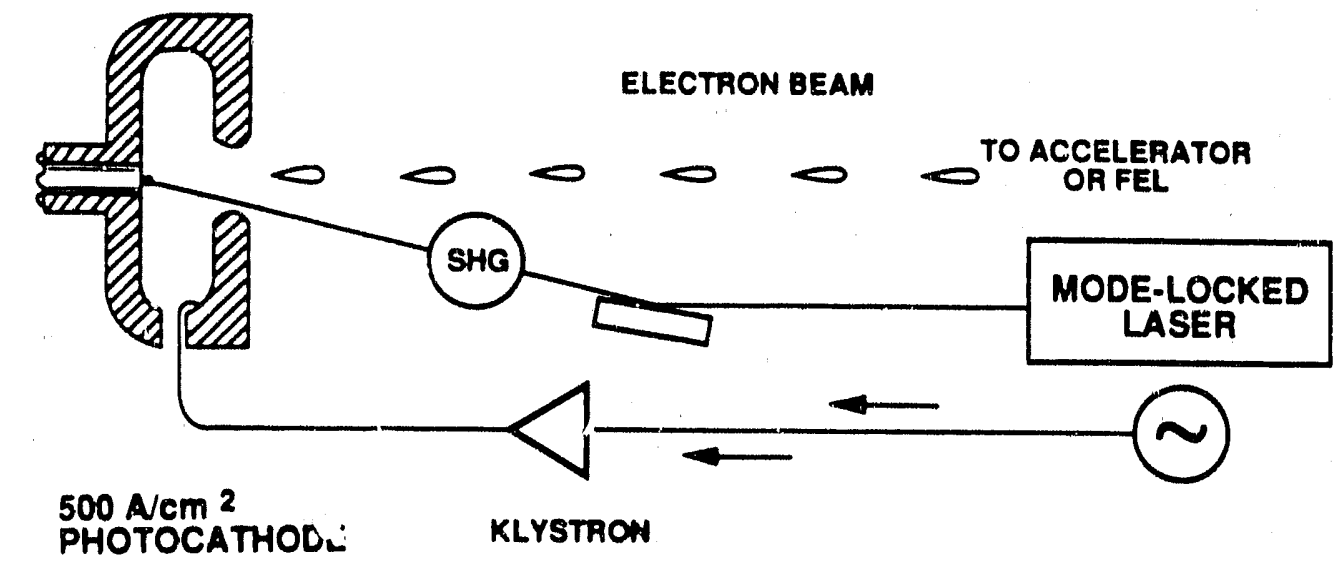

Eig.5. Basic concept of the laser-irradiated photoinjector. The photocathode is mounted in the first accelerator cavity where emitted picosecond elentron pulsus are rapidly accelerated by a high-gradient electric field, thereby minimizing emittance growth.

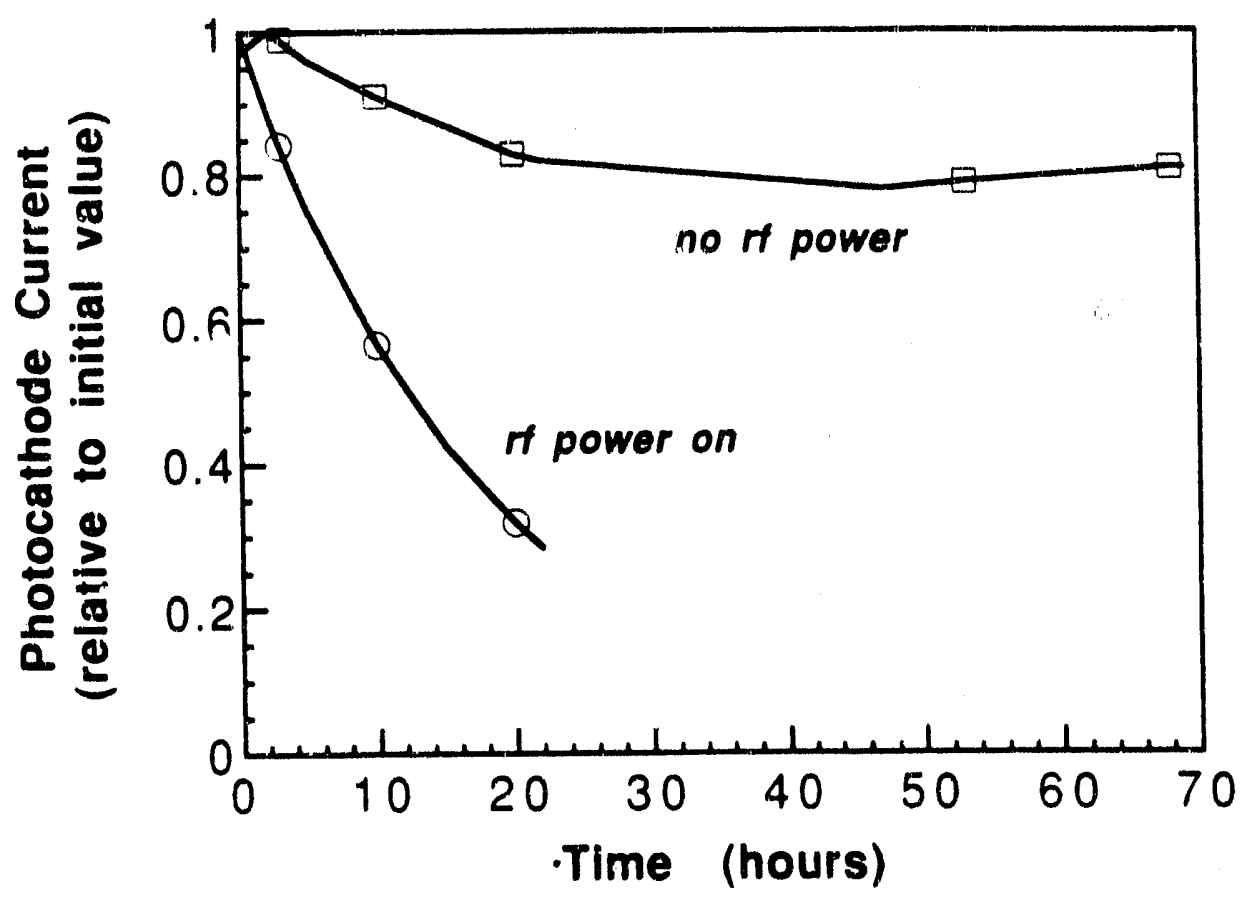

Eig.6. Initial tests of $\mathrm{CsK}_{2} \mathrm{Sb}: 0$ photocathode current emission when mounted on the wall of the first infector linac cell: with and without $r$ accelerating power. Glow-discharge treatment and ongoing electron-indused desorption of contaminants is expected to greatly lengthen the cathode lifetime. After Volz. 49 
cathodes produced 1-A average current, but due to loss of Cs, they only had a short, 0.5-hr lifetime (1/e). Addition of $k$ in the cathode fabrication process resulted in csk2sb:0 surfaces with greatly reduced Cs loss rates which immediately extended the lifetime to two hours. With continued operation of this cathode formulation within the first accelerator cavity, an 18-hour lifetime with full rf-drive power was obtained at a given laser intensity.46 The effective lifetime has been extended even more by raising the drive laser power level enough to compensate for the declining quantum efficiency. Further improvement is expected when glow-discharge cleaning of the cavity walls is implemented to augment electron-beam desorption of contaminant gases. This procedure has proven effective in conditioning the Arookhaven NSIS storage rings. 52

It appears that semiconductor photocathodes with high quantum efficiency are more susceptible to degradation by contamination than metal photncathodes, e.g. Y. However, to generate electron pulses with large charges, e.g. 5-10 nu/pulse, as just implied, it is necessary to have the product of the drive-laser pulse energy and QE be sufficientiy large. The experience of the Los Alamos EEL team is that a photoinjector with a Csk 2 Sb-cathoce irradiated with $532-\mathrm{nm}$ laser pulses produces a micropulse charge of $Q$ (nC/pulse) $-4.5 Q E(z) x$ $E(\mu \mathrm{J} / \mathrm{pulse}) .53$ Although it becomes increasingly difficult and expensive to generate higher-energy, cw-modelocked laser pulses in the green or ultraviolet, it is possible to trade-off low-QE cathodes with longer lifetimes fox a more powerful and expensive drive laser.

The concentrated efforts of several research groups $46-48$ to implement photoinjectors on if linacs designed for EELs should eventually make rf linacs reliable sources of high-current, lowemittance electron beams. If the high brightness of such beams can be maintained without degradation during acceleration to high energy, then numerical simulations predict that EEL gain should be high enough for oscillator operation at wavelengths as short as $4 \mathrm{~nm}, 6,24$ The first FEL experiments with a photoinjector, conducted by a Stanford University-Rocketdyne team, demonstrated lasing at $3.1 \mathrm{\mu m}$ with laser-enhanced electron emission from a LaBG ri gun.48 Meanwhile, a high-current photoinjector has been integrated into the Los Alamos infrared FEL system. As reported by Feldman et al.,54 initial measurements of the beam quality at $17 \mathrm{MeV}$ were in agreement with predicted values for the normalized design emittance, $\sim 30 \pi$ and $550 \pi \mathrm{mm}-\mathrm{mr}$ for $5-\mathrm{nC}$ and $10-\mathrm{nC}$ bunches, respectively.

Besonator Mi-rons for XUV FELs: FEL oscillator operation in the XUV will require resonator mirrors with sufficiently high retroreflectance to provide a suistantial advantage over a single-pass amplifier. By setting the reflectance requirement at an arbitrary value of 2408 for each of the two end mirrors the mirror losses will have to be offset by single-pass gain $>600 \%$, which is attainable.

Below $100 \mathrm{~nm}$, few materials have reflectance exceeding $40 \%$ for normal incidence. For wavelengths from 60-100 nm, polished chemically vapor-deposited (CVD) silicon carbide (SiC), depositec on hot SiC substrates, exhibits a reflectance between $40 \%$ to $50 \%$ at normal incidence. 55 In the same spectral region, the reflectance of polish- 
ed type-I diamond reportedly exceeds this by a few per cent.56 From $80 \mathrm{~nm}$ to $100 \mathrm{~nm}$, the reflectance of unoxidized Al films goes from $40 \%$ to >90\%.57 Einally, in the range from 10 to $20 \mathrm{~nm}$, multilayer reflectors of Mo and $S i$ are available commercially with reflectance typically between 40 to 508.58

An additional requirement for $E E L$ resonators is that the total beam-induced thermal distortion of the mirror surfaces must be restricted to a small fraction $\left(\sim y^{\prime} / 4\right)$ of the operating wavelength. Thus, high mirror reflectance $295 \%$, $i . e$; absorptance $55 \%$, is essential.24,40 The multifacet XUV metal mirror design proposed by Newnam59,60 should satisfy both requirements in certain spectral regions (retroreflectance 2408 and 558 absorptance per facet). This mirror system exploits the phenomenum of total external reflectance (TER) at large angles of incidence. As pointed out by vinogradov et al.,61 materials with refractive index (both real and imaginary parts) sufficiently less than unity can provide surprisingly high retroreflectance by using a sequence of reflections beyond the critical angle, typically larger than $60^{\circ}$. Unoxidized Al and crystaliine Si, for example, have the necessary optical constants to attain $\geq 40 \%$ retroreflectance from $35 \mathrm{~nm}$ to $100 \mathrm{~nm}$.

An EEL ring resonator incorporating multifaceted retroreflectors is shown in Fig. 7. The appropriate reflective coatings will depend on the spectral operating rarge: $235-100 \mathrm{~nm}$ using Al films or crystalifine silicon, and 9-14 nm with $A g, R u$, and Rh films.59-61 other single-layer films that could exhibit sufficiently high TER in the wavelength range intermediate between 14 and $35 \mathrm{~nm}$ include $Y$ and Se.62 An important advantage of these single-layer reflectors is that they can be deposited on the multifaceted $S i$ or SiC mirror substrates without removing them from the ring resonator.

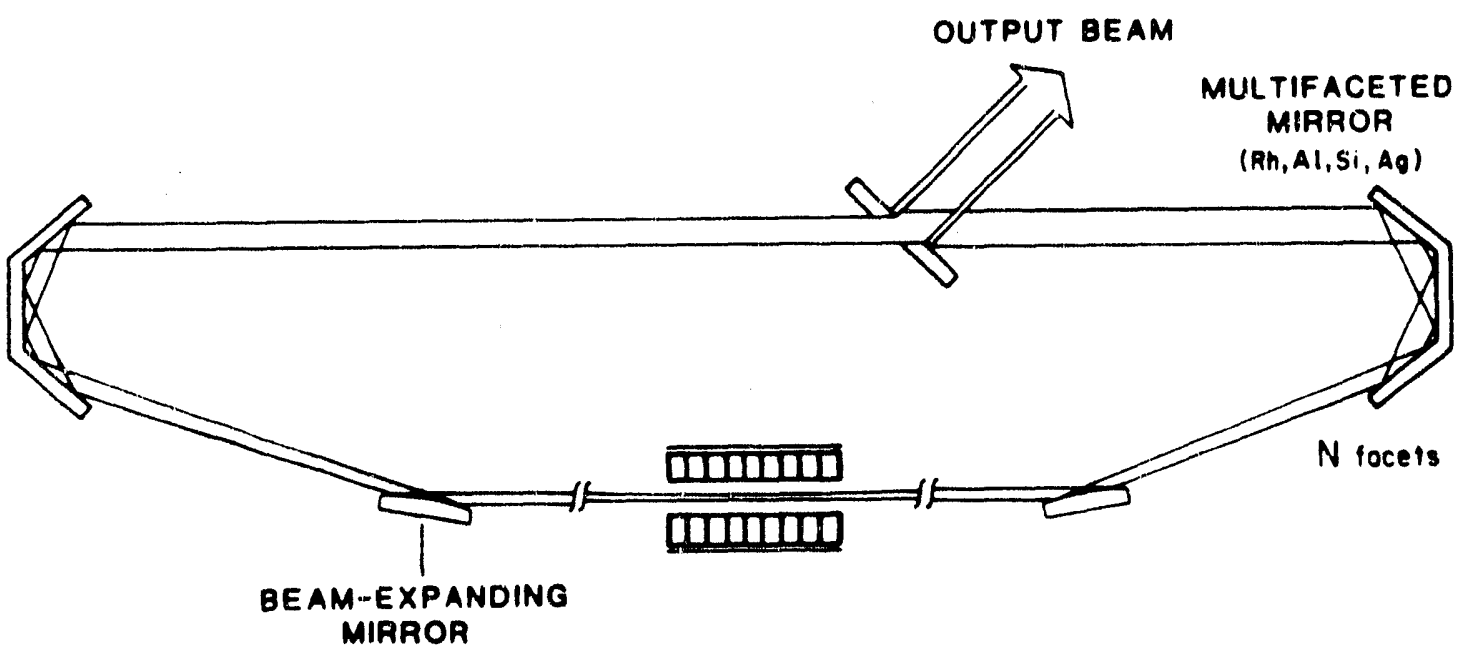

Eig.7. Multifacet, all-metal mirrors based on total external reflectance at large angles of incidence $\left(\sim 80^{\circ}\right)$ will provide the necessary 2408 retroreflection for EEL ring oscillators over broad spectral ranges in the xUV. Intracavity, grazing incidence, hyperboloidal mirrors diverge the beam to reduce beam-induced thermal distortion on the multifacet mirrors and allow shorter resonator lengths. The off-axis paraboloidal figure of the upper facet of the multifacet mirrors collimates the reflected beam. After Newnam. 59 
Los Alamos researchers have experimented primarily with aluminum thin films deposited with an electron gun on polished silicon substrates in an ultra-high vacuum (UHV) of $10-10$ Torr to minimize surface oxidation. At $58.4 \mathrm{~nm}$ using a He-discharge source and $80^{\circ}$ incidence, scott 63 measured the in situ reflectance of single, Al-coated mirrors to be $98.7 \pm 28$. Under similar conditions, the net retroreflectance of a nine-facet Al-coated retroreflector, was $89 \pm 38$, in agreement with the single-facet measurement. This value of retroreflectance is more than a factor-of-two higher than reported for any other XUV mirror in the vicinity of $60 \mathrm{~nm}$. At 30.4 $\mathrm{nm}$, additional UHV single-mirror measurements indicated that this same nine-mirror array should have a retroreflectance value of $\sim 33 \%$. Contamination by oxide and carbon epifilms can severely increase the absorption of metal films and thereby prevent TER. Using an ellipsometer, scott et al.64-66 measured the growth rates of oxide epifilms in situ on Al and Si films in different vacuum environments. Figure 8 shows that a monolayer of oxide grows on Al in about one hour in a constant 10-8 Torr partial-pressure environment of oxygen (or water vapor, not shown). At five times higher pressure ( $2 \times 10^{-7}$ Torr), an oxide monolayer on $S i$ takes more than an hour to form (Eig. 9). Fortunately, at sufficient vacuum levels with low oxygen and water partial pressures, the oxidation of aluminum films proceeds at a much slower rate. For example, a two-week exposure of a fresh aluminum film in a $2 \times 10^{-9}$ Torr vacuum, primarily with residual He, resulted in formation of only $1 / 4$ of an oxide monolayer (see Eig. 10).64 The net result on the retroreflectance is shown in Fig. 11. Measurements after four weeks indicated negligible additional growth of the oxide layer.67

The growth of carbon contaminant films on optical surfaces irradiated by intense $x$-rays and effective cleaning techniques for non-oxidizing materials are well documented.68-70 However, carbonfilm growth caused by narrow-bandwidth, Low-photen-energy radiation has not yet been adequately examined. For the wavelength range $230 \mathrm{~nm}$ where $A I$ and $S i$ are effective retrorereflectors, it is expected that that the rate of contamination will be much less severe than experienced with broad-band, higher-energy synchrotron radiation photons.

It is possible that an initial clearing of the UHV system of carbonaceous compounds by using the rf-discharge technique developed by Johnson et al.,68,69 (followed by in situ deposition of the reflecting films) willyleld adequately long lifetimes with high reflectance. Another option is to periodically overcoat the contaminated metallic films with fresh material to offset the effects of gradual deterioration that may occur while in the FEL resonator. of course, the total thickness of the films must not become too great lest surface roughness increase. An ion gun, mounted in the vacuum chamber and used with specific beam parameters, may be an effective way to periodically sputter away aged films prior to evaporation of a fresh film.

Undulator beam tube: During transit through the narrow beim tubes within small-gap undulators, it is possible that inadequate vacuum, due to poor pumping conductance, might cause beam emittance growth 


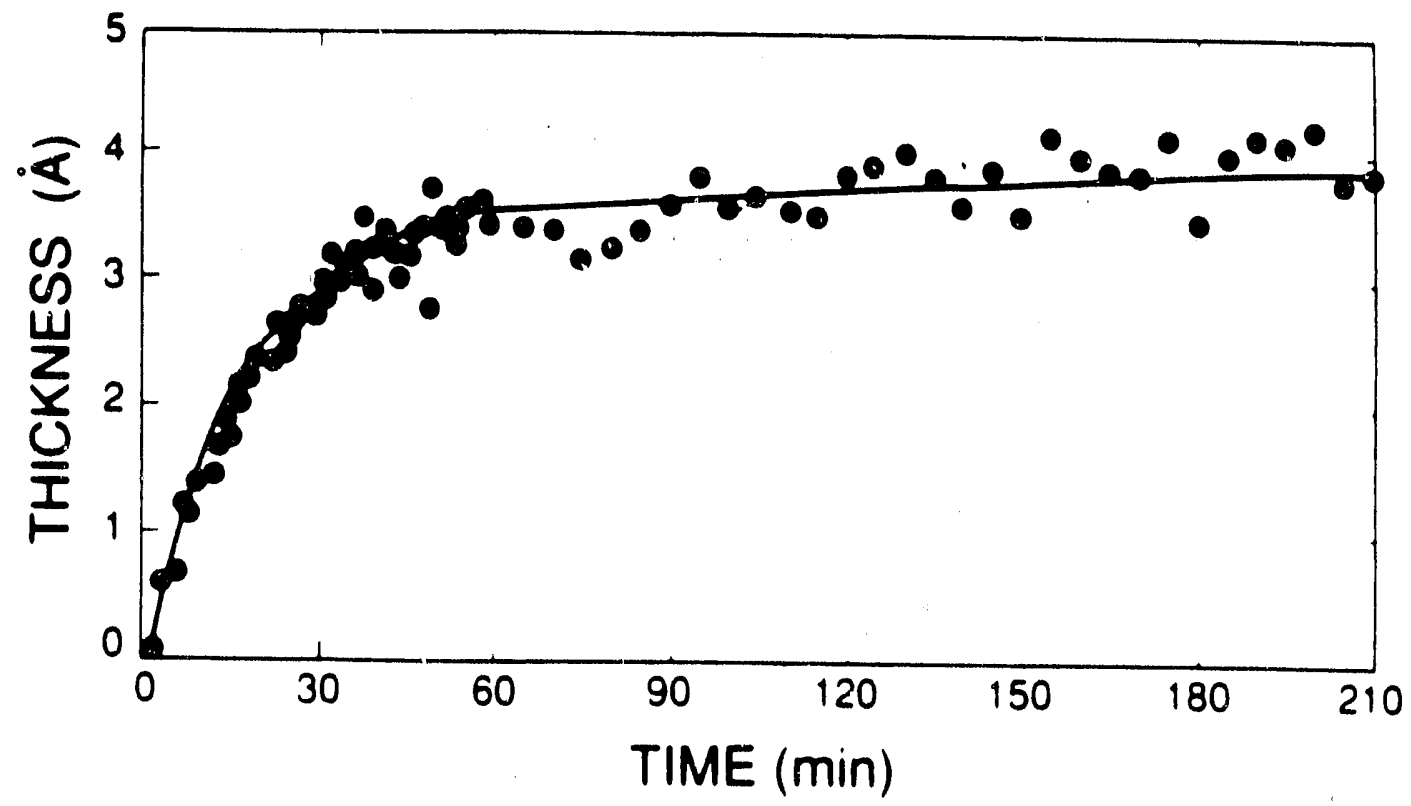

Fig.8. Ellipsometer measurement of the formation of a single monolayer of surface oxide on a fresh aluminum film exposed to $2 \times 10^{-8}$ Torr of oxygen. After scott et al.64

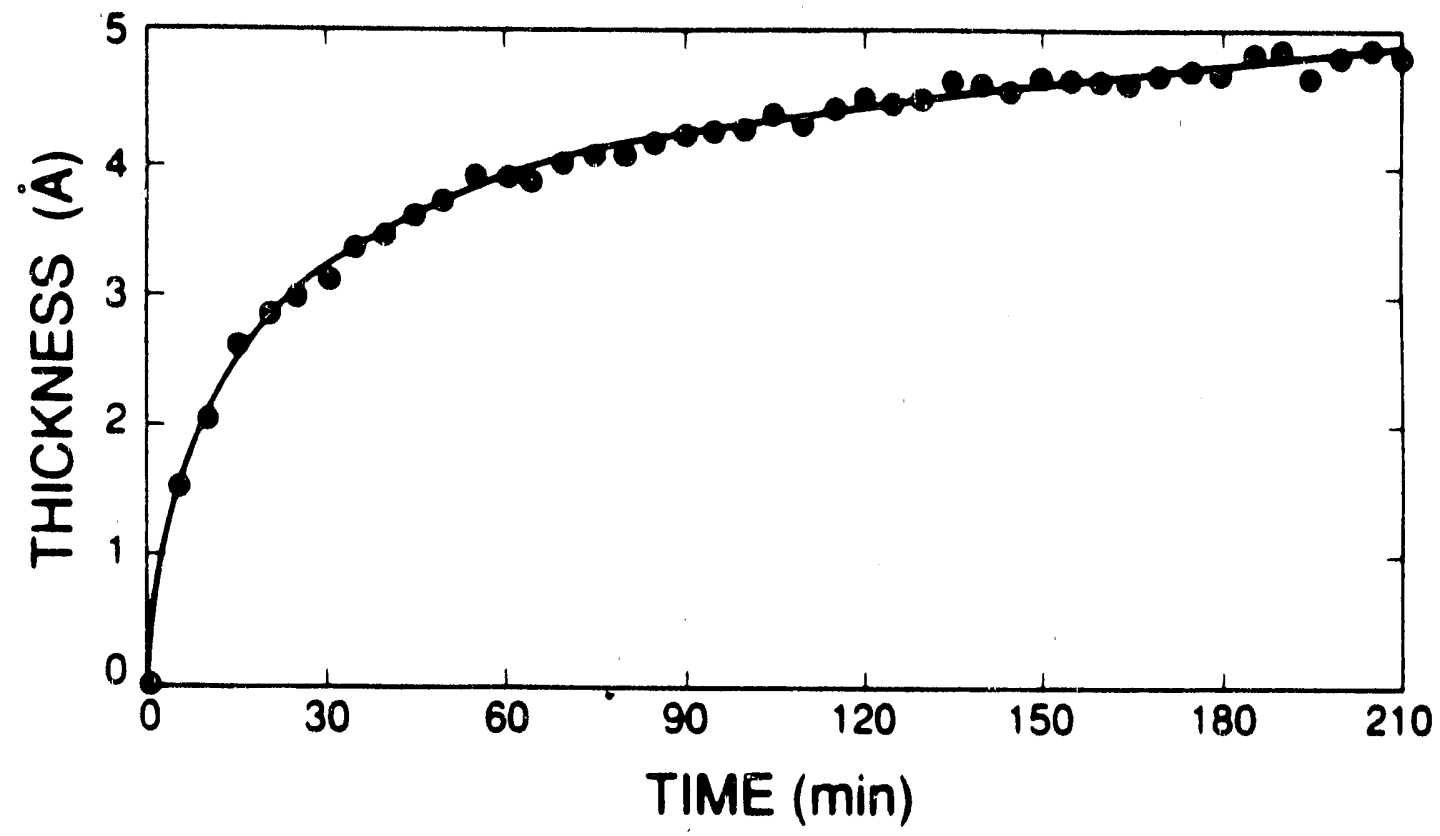

Fig.9. Ellipsometer measurement of the formation of a single monolayer of surface oxide on a fresh silicon film exposed to 10-7 Torr of oxygen. After scott et al.64 


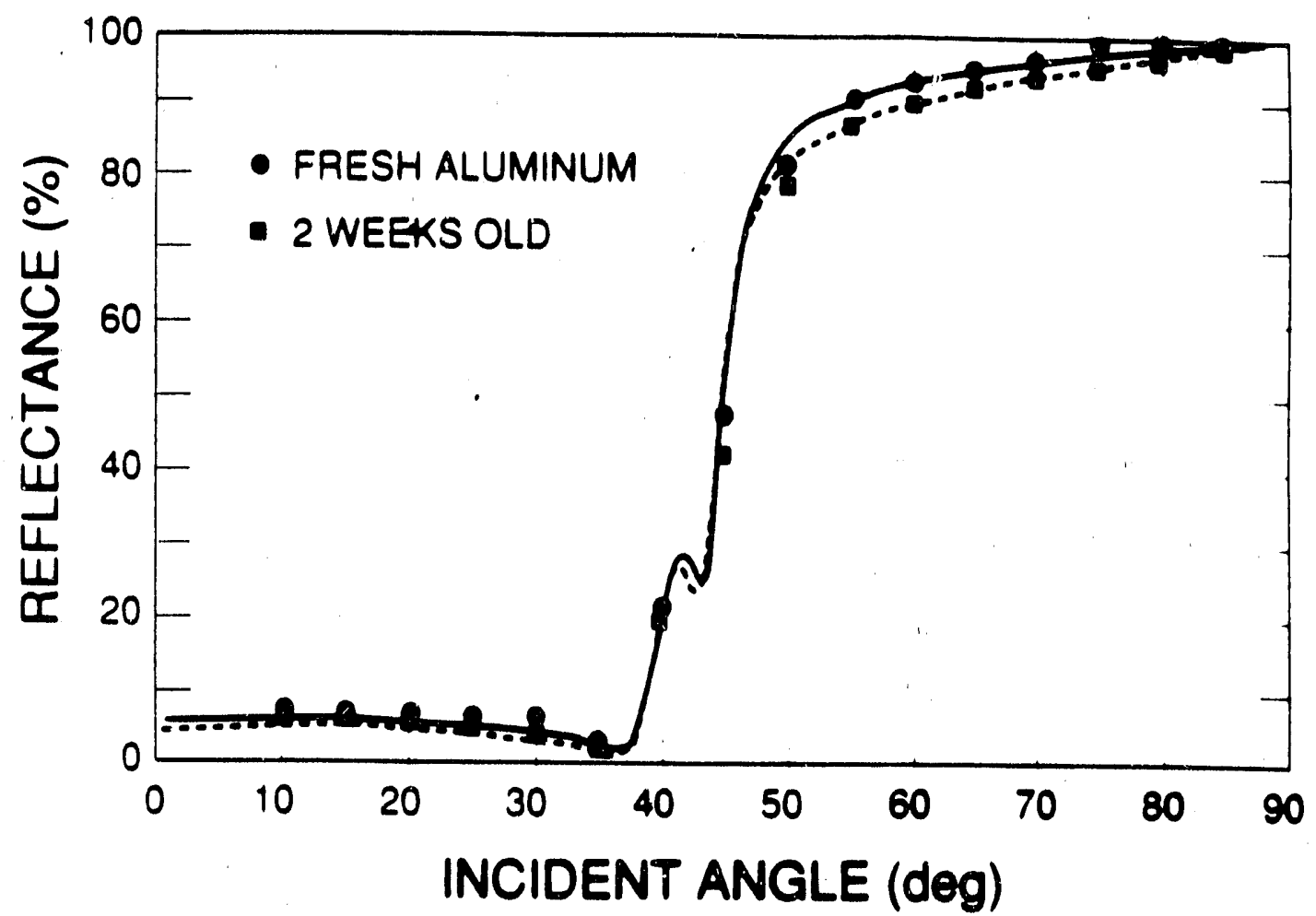

Eig.10. Reflectance vs angle of incldence for a fresh aluminim film overcoating a previously deposited and oxidized Al film (solid line). This same film was measured again after two weeks in a UHV system at a helium pressure of $22 \times 10^{-9}$ Torr (dotted line). The interference effect between $35^{\circ}$ and $45^{\circ}$ is due to subsurface reflections. After scott et al. 64

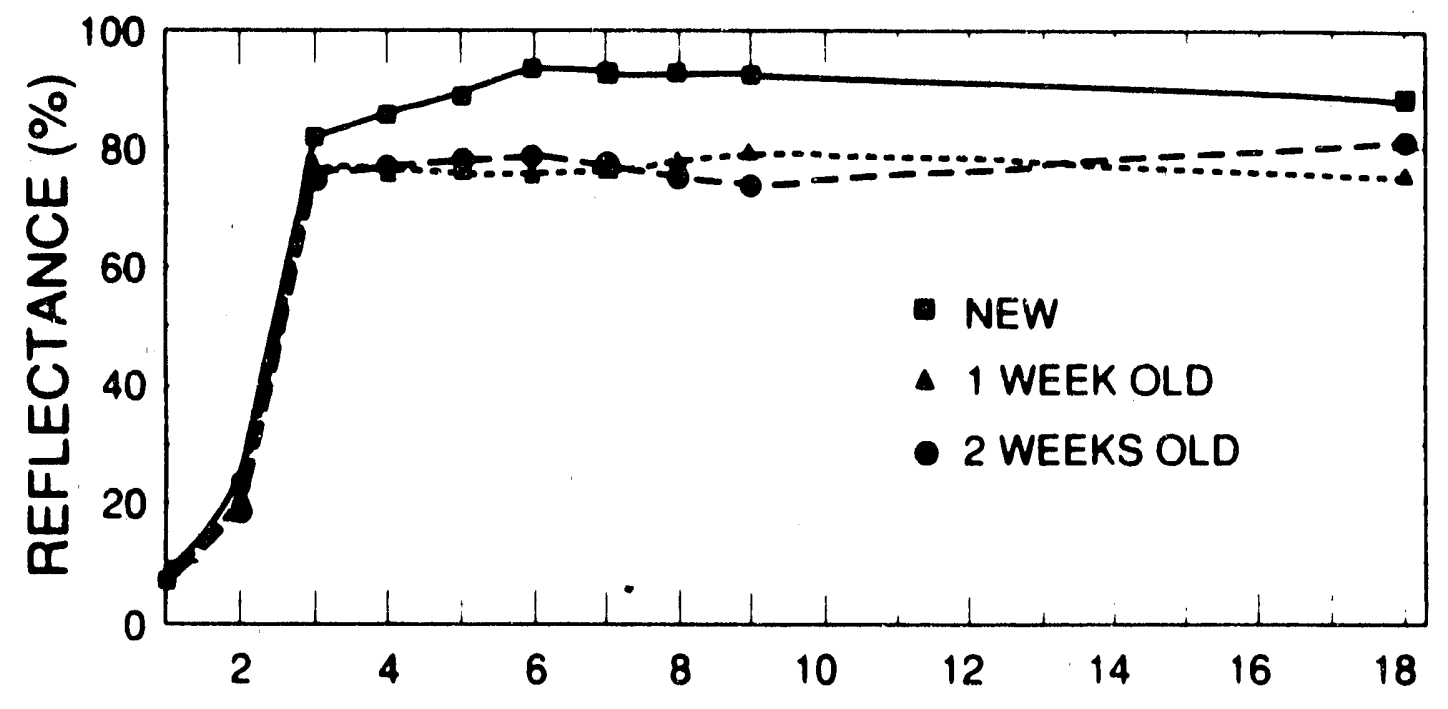

\section{- NUMBER OF FACETS}

Fig.11. Net retroreflectance vs number of facets in a multifacet mirror calculated from the data of Fig. 10 . No change is seen between one and two weeks. After scott et al. 64 
via ion trapping. This could lead directly to restricted FEL gain in both single- and especially multiple passes of the same electron beam through the undulator, as in a storage-ring EEL configuration. Generally, small-gap undulators are not used in storage rings to avoid beam-scraping losses that restrict the beam lifetime.

Evidently, no problem is experienced with large-bore, short undulators such as the $1.3-\mathrm{m}$ undulator used in the University of Paris, ACO-storage-ring FEL. Likewise, with magnet gaps of 4 to $9 \mathrm{~mm}$ and undulator lengths of 1 to $5 \mathrm{~m}$, no beam deterioration problems have yet been experienced by developers of single-pass, rf-linacdriven FELs. For example, no gross emittance growth was observed during a Los Alamos test using 10-3-T vacuum in a short, $1-m$ undulator.71 However, at grossly higher pressures 21 torr of hydrogen gas, beam degradation was observed in the stanford University If-linac FEL.72 Even in this special case, where the gas was intentionally used to tune the EEL to short wavelengths, addition of a small amount of electron-attaching gas eliminated the beam scattering of the 4-ps pulses. Alternately, adjustment of the beam focal position compensated for the gas.73 one may conclude that moderately poor vacuum conditions in a small-gap undulator will only be a problem for EELs in recirculating accelerators such as storage rings. The possible impact on an electron beam during its single-transit through a multiple-fel system driven by an rf-linac, such as the proposed Los Alamos facility, is not likely to be significant.

\section{SUMMARY}

Eree-electron lasers represent the next generation of coherentradiation sources with peak- and average-power output capabilities that should surpass those of any existing, continuously tunable photon source by many orders-of-magnitude. Recent advances of EEL component technologies (electron linac, resonator mirrors, and magnetic undulator) should enable these devices to operate in the XUV, from $<4 \mathrm{~nm}$ to $100 \mathrm{~nm}$, as well as at more easily achieved longer wavelengths. Important developments include a high-brightness photoinjector, multifaceted resonator mirrors with retroreflectance $>40 \%$, and high-precision undulators with $>200$ periods. An If-linac-based, multiple-EEL user facility, spanning wavelengths from $1 \mathrm{~nm}$ to $100 \mu \mathrm{m}$, has been designed and proposed by Los Alamos National Laboratory for scientific research and those industrial applications requiring expanded photon-parameter ranges. To enable such a facility to operate without significant degradation over long periods, contamination of the particular EEL components listed above must be prevented or controlled. Provision for UHV environments plus glow-discharge cleaning treatments should greatly mitigate contamination problems in future XUV FELs.

\section{ACKNOWLEDGMENTS}

Discussions with members of the Los Alamos Eree-Electron Laser team were invaluable in preparing this manuscript. Particular thanks go to scott Volz and Richard sheffield regarding photocathode life- 
measurements, Donald Feldman and Roger Warren for characterization of EEL operation, Marion scott on reflector contamination, and John Goldstein on XUV-FEL numerical simulations.

\section{REEERENCES}

1. I. B. Drobyazko, G. N. Kulipanov, V. N. Litvinenko, I. V. Pinayev, V. M. Popik, I. G. Silvestrov, A. N. Skrinsky, A. S. Sokolov, and N. A. Vinokurov, in Free-Electron Lasers II, $Y$. Petroff, Ed., SPIE Vol. 1133, pp. 2-10, (1989).

2. G. N. Kulipanov, V. N. Litvinenko, I. V. Pinayev, V. M. Popik, A. N. Skrinsky, A. Sokolov, and N. A. Vinokurov, Nucl. Instr. and Methods in Phys. Res. A296, 1-3 (1990).

3. R. Prazeres, J. M. Ortega, C. Bazin, M. Bergher, M. Billardon, M. E. Couprie, M. Velghe, and $Y$. Petroff, Nucl. Instr. and Methods in Phys. Res. A272, 68-72 (1988).

4. R. Prazeres, P. Guyot-sionnest, D. Jaroszynski, J. M. Ortega, M. Billardon, M. E. Couprie, and M. Velghe, Nucl. Instr. and Methods in Phys. Res., to be publ., 1991.

5. J. M. J. Madey, in Free Electron Generation of Extreme Ultraviolet Coherent Radiation, J. Madey and C. Pelligrini, Eds., AIP Conf. Proc. No. 118, (Amer. Inst. Phys., NY, 1984), Pp. 12-43.

6. J. C. Goldstein, in Proc. of the ICFA Workshop on Low Emittance $e^{-}-e^{+}$Beams, J. B. Murphy and C. Pelligrini, Eds., (Brookhaven Nat1. Lab., Upton, NY) BNL Rept. 52090; pp. 180-196, (1987).

7. H. Wiedemann, in Int'1. Conf. on Insertion Devices for synchrotion sources, R. Tatchyn, and I. Lindau, eds., Proc. SPIE Vol. 582, pp. 110-117, (1986).

8. J. E. La Sala, D. A. G. Deacon, and J. M. J. Madey, Nucl. Instr. and Methods in Phys. Res. A250, 262-273 (1986).

9. J. E. La Sala, D. A. G. Deacon, and J. M. J. Madey, in Int'l. Conf. on Insertion Devices for Synchrotron Sources, op. cit., pp. $156-162$, (1986).

10. J. M. J. Madey, S. V. Benson, and B. Burnham, Nucl. Instr. and Methods in Phys. Res., to be publ., 1991.

11. S. V. Benson, J. M. J. Madey, and W. Ying, Nucl. Instr. and Methods in Phys. Res.., to be publ., 1991.

12. N. Marquardt, Proc. of 1989 IEEE Particle Accelerator Conf., E. Bennett and $J$. Kopta, Eds., IEEE Cat. No, 89CH2669-0 (IEEE Serv. Center, Piscataway, NJ, 1989), Vol.2, p. 780-782.

13. D. Nolle, F. Brinker, M. Negrazus, D. Schirmer, and K. Wille, Nucl. Instr. and Methods in Phys. Res. A296, 263-269 (1990).

14. B. E. Newnam, J. C. Goldstein, J. S. Fraser, and R. K. Cooper, in Free-Electron Generation of Extreme Ultraviolet Coherent Radiation, op. cit., pp. 190-202.

15. J. C. Goldstein, B. E. Newnam, R. K. Cooper, and J. C. Comly, Jr., in Laser Techniques in the Extreme ultraviolet, S. E. Harris and I. B. Iucatorto, Eds., AIP Conf. Proc. No. 119 (Amer. Inst. Phys., NY, 1984), pp. 293-303.

16. J. C. Goldstein, B. D. McVey, B. E. Newnam, in short Wavelength Coherent Radiation: Generation and Applications, D. T. Attwood and J. Bokor, Eds., AIP Conf. Proc. No. 147, (Amer. Inst. Phys., NY, 1986), Pp. 275-290. 
17. J. C. Goldstein, B. D. Movey, and B. E. Newnam, in Int'1. Conf. on Insertion Devices for synchrotron sources, op. cit., pp. 350-360, (1986).

18. J. C. Goldstein and B. D. McVey, Nucl. Instr. and Methods in Phys. Res. A259, 203-¿09 (1987).

19. J. C. Goldstein, B. D. McVey and C. J. Elliott, Nucl. Instr. and Methods in rhys. A272, 177-182 (1988).

20. B. E. Carlsten and K. C. D. Chan, Nucl. Instr. and Methods in Phys. Res. A272, 208 (1988).

21. B. E. Carlsten, Nucl. Instr. and Methods in Phys. Res. A285, 313-319 (1989).

22. B. E. Newnam, Nucl. Instr. and Methods in Phys. Res. B40/41. 1053-1057 (1989).

23. B. E. Newnam, 1988 Inear Accelerator Conf. Proc., C. Leemann, Ed., CEBAF-Rept. 89-001, pp. 290-294, June, 1989.

24. J. C. Goldstein, B. D. McVey, and B. E. Newnam, Nucl. Instr. and Methods in Phys. Res. A296, 288-291 (1990).

25. J. C. Goldstein, R. W. Warren, and B. E. Newnam, Nucl. Instr. and Methods in Phys. Res., to be publ., 1991.

26. I. Ben-zvi, L. H. Yu, S. Krinsky, and M. White, Nucl. Instr. and Methods in Phys. Res., to be publ., 1991.

27. D. W. Eeldman, R. W. Warren, B. E. Carlsten, W. E. Stein, A. H. Lumpkin, S. C. Bender, G. Spalek, J. M. Watson, I. M. Young, J. S. Fraser, J. C. Goldstein, H. Takeda, T. F. Wang, R. B. Feldman, R. K. Cooper, W. J. D. Johnson, and C. A. Brau, IEEE J. Quantum Electron. es-23, 1476-1488 (1987).

28. R. W. Warren, J. E. Sollid, D. W. Feldman, W. E. Stein, W. J. Johnson, A. H. Lumpkin, and J. C. Goldstein, Nucl. Instr. and Meth. in Phys. Res. A285, 1-10 (1989).

29. D. W. Eeldman, in Free-Electron Lasers II, op. cit., pp. 36-53.

30. D. W. Feldman, S. C. Bender, B. E. Carlsten, J. Early, R. B. Eeldman, W. J. D. Johnson, A. H. Lumpkin, P. G. O'Shea, W. E. Stein, R. L. Sheffield, and $K$. McKenna, Nucl. Ingtr. and Meth. in Phys. Res., to be publ., 1991.

31. S. V. Benson, J. Schultz, B. A. Hooper, R. Crane, and J. M. J. Madey, Nucl. Instr. and Meth. in Phys. Res. B272, 22-28 (1988).

32. S. V. Benson, W. S. Fann, B. A. Hooper, J. M. J. Madey, E. B. Szarmes, B. Richman, and L. Vintro, Nucl. Instr. and Meth. in Phys. Res. A296, 110-114 (1990).

33. R. L. Tokar, L. M. Young, A. H. Lumpkin, B. D. McVey, L. E. Thode, S. C. Bender, K. C. D. Chan, A. D. Yeremian, D. H. Dowell, A. R. Lowrey, and D. C. Quimby, Nucl. Instr. and Meth. in Phys. P.es. A296, 115-126 (1990).

34. D. H. Dowell, M. L. Laucks, A. R. Lowrey, M. Bemes, A. Currie, P. Johnson, K. McCrary, J. Adamski, D. Pistoresi, D. R. Shoffstall, M. Bentz, R. Burns, R. Hưdyma, K. Sun, W. Mower, R. Tokar, A. H. Lumpkin, S. Bender, B. McVey, J. Goldstein, and D. Shemwell, Nucl. Instr. and Meth. in Phys. Res., to be publ., 1991.

35. J. B. Murphy and C. Pelligrini, J. Opt. Soc. Am. -B 2, 259-264 (1985).

36. T. E. Wang, J. C. Goldstein, B. E. Newnam, and B. D. McVey, Intl. J. Electronics 65, 589-595 (1988). 
37. S. D. Conradson and B. E. Newnam, in Free-Electron Lasers and Applicatio.ns, D. Prosnitz, Ed., Proc. SPIE Vol. 1227, 134-.44 (1990).

38. Free-Electron Laser Applications in the Ultraviolet, OSA Tech. Digest Series, Vol. 4, D. A. G. Deacon and B. E. Newnam, Eds., (Optical Soc. Am., Washington, D.C.), March 2-5, 1988.

39. B. D. McVey, Nucl. Instr. and Methods in Phys. Res. A250, 449 (1986).

40. B. D. McVey, J. C. Goldstein, R. D. McFarland, and B. E. Newnam, in Laser Induced Damage in Optical Materials: 1992, $\mathrm{H} . \mathrm{E}$. Bennett, A. H. Guenther, L. L. Chase, B. E. Newnam, and M. J. Soileau, Eds., (Natl. Inst. Stand. and Tech. U.S.) Spec. Rubl., SPIE Vol. 1441, to be publ., 1991.

41. Report of the ALS/SSRL Users Workshop, May 9-11, 1983, A. I. Bienenstock, T. Elioff, and E. E. Haller, co-chairmen, Lawrence Berkeley Laboratory Pub-5095, 1983.

42. An ALS Handbook, Lawrence Berkeley Laboratory PUB-643 Rev.2, April, 1989.

43. J. S. Fraser and R. I. Sheffield, IEEE J. Quantum Electron. OE-23, 1489-1496 (1987).

44. R. L. Sheffield, E. R. Gray, and J. S. Fraser, Nucl. Instr. and Methods in Phys. Res. A272, 222-226 (1988).

45. R. I. Sheffield, in Proc. of 1989 TEEE Particle Accelerator Conf., op. cit., pp. 1098-1102 (1989).

46. R. I. Sheffield, W. D. Cornelius, D. C. Nguyen, R. W.. Springer, B. C. Lamartine, E. R. Gray, J. M. Watson, and J. S. Fraser, in 1988 Linear Accelerator Conf. Proc., op. cit. pp. 520-522.

47. K. Batchelor, I. Ben-zvi, R. Fernow, J. Gallardo, H. Kirk, C. Pelligrini, and $A$. van Steenbergen, Nucl. Instr. and Methods in Phys. Res. A296, 239-243 (1990).

48. M. Curtin, G. Bennett, R. Burke, A. Bhowmik, P. Metty, S. Benson, and J. M. J. Madey, Nucl. Instr. and Methods in Phys. Res. A296, 127-133 (1990).

49. S. K. Volz, Isos Alamos Natl. Laboratory, priv. commun., 1990.

50. T. Kobari and H. J. Halama, J. Vac. Soc. Tech. A5, 2355 (1987).

51. A. G. Mathewson, Synchrotron Radiation News 3, 13-17 (1990).

52. H. C. Hseuh, T. S. Chou, and C. A. Christianson, J. Vac. Sci. Technol. A3, 518-522 (1985).

53. F. G. O'Shea, Los A.lamos Natl. Lab., priv. commun., 1990.

54. D. W. Feldman, W. D. Cornelius, S. C. Bender, B. E. Carlsten, P. G. O'Shea, and R. L. Shezfield, in Free Electron Lasers and Applications, op. cit., pp. 2-13.

55. W. J. Choyke, and E. U. Palik, in Handbook of optical Constants, E. D. Palik, Ed., (Academic Press, NY, 1985), Pp. 587-596.

56. R. A. Roberts and W. C. Walker, Phys. Rev. 161, 730-735 (1967).

57. D. Y. Smith, E. Shiles and M. Inokuti, in Handboek ef eptical Censtants of solids, op. cit., pp. 369-406.

58. D. Roussel-Dupre, Los Alamos Natl. Laboratory, verbal report on measurements of Mo/Si mirrors supplied by Ovonics, Inc., 1989.

59. B. E. Newnam, in Laser Induced Damage in Optical Materials: 1985, H. E. Bennett, A. H. Guenther, D. Milam, and B. E. Newnam, Eds., (Natl. Bur. Stand., Wash., DC), NBS Spec. Publ. 746, 261-269 (1988). 
60. B. E. Newnam, U.S. Patent No. 4,917,447 issued Apri1 17, 1990.

61. A. V. Vinogradov, I. V. Kozhevnikov, and A. V. Popov, Opt. Commun. 47, 361-363 (1983).

62. T.-Y. Hung and P. L. Hagelstein, Paper TuB4 presented at the 1990 Annual Mtng. of the opt. Soc. America, Nov. 4-9, 1990, Boston.

63. M. L. Scott, in OSA Proc. on Short Wavelength Coherent Radiation: Generation and Applications, R. Falcone and J. Kirz, Eds., (Opt. Soc. Am., Washington, DC, 1988), Vol. 2, pp. 322-324.

64. M. I. Scott, P. N. Arendt, B. J. Cameron, J. M. Saber and B. E. Newnam, Appl. Opt. 27, 1503-1507 (1988).

65. M. I. Scott, P. N. Arendt, B. Cameron, R. Cordi, B. Newnam, D. Windt, and W. Cash, in X-Ray Imaging II (1986), I. V. Knight, and D. K. Bowen, Eds., Proc. SPIE Vol. 691, pp. 20-27, (1986).

66, M. I. Scott, P. N. Arendt, B. J. Cameron, and B. E. Newnam, in Soft X-Ray Optics and Technology, E.-E. Koch, and $Q$. SchmahI, Eds., Proc. SPIE Vol. 733, pp. 156-162, (1987).

67. M. I. Scott, Los Alamos Natl. Lab., priv. commun., 1988.

68. E. D. Johnson, S. I. Hulbert, R. E. Carrett, G. R. Williams, and M. L. Knotek, Rev. Sci. Instrum. 58, 1042-1045 (1987).

69. E. D. Johnson and R. F. Garrett, Nucl. Instr. and Methods in Phys. Res. A266, 381-385 (1988).

70. V. Rehn, in Topical Conf. on Vacuum Design of synchrotron Light Sources, S. Bader, Ed., AIP Conf. Proc. (Amer. Inst. Phys., NY), to be publ. in 1991 .

71. D. W. Eeldman, Los Alamos Nat1. Lab., priv. Commun., 1990.

72. A. S. Eisher, R. H. Pantell, J. Feinstein, T. L. Deloney, M. B. Reid, and W. M. Grossman, Nucl. Instr. and Methods in Phys. Res. A250, 337-341 (1986).

73. A. S. Fisher, R. H. Pantell, M. B. Reid, J. Feinstein, A. H. Ho, M. Ozcan, and H. D. Dulman, Nucl. Instr. and Methods in Phys. Res. A272, 89-91 (1988). 

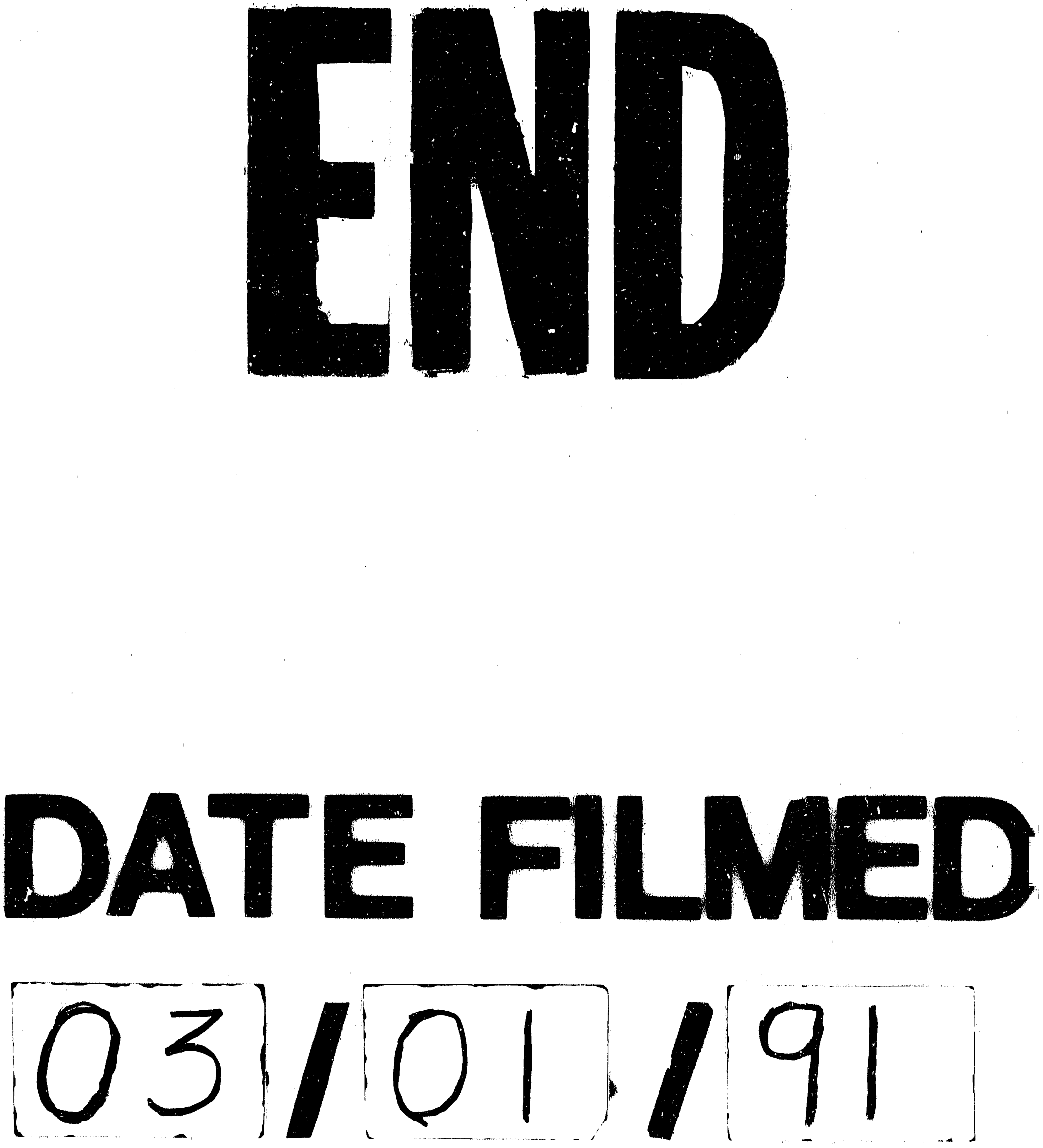
